\title{
AS REDES SOCIAIS E O USO DA INFORMAÇÃO ENTRE OS PESQUISADORES DE ALIMENTOS FUNCIONAIS DA UEL
}

\section{Jorge Luis Rodrigues \\ Maria Inês Tomaél}

\section{Resumo:}

As redes desenvolvem-se pelos contatos que atores mantêm, provocam a construção social do indivíduo e, quando vistas por suas relações, podem identificar coesões e similaridades, em ações coadunadas de indivíduos que agem como um único corpo social. Estudar o uso da informação na rede de alimentos funcionais da Universidade Estadual de Londrina (UEL) foi o principal objetivo deste trabalho. A rede estudada é caracterizada por um conjunto de pesquisadores que buscam o desenvolvimento da especialidade - alimentos funcionais. Por meio da metodologia de Análise de Redes Sociais (ARS) foram identificados os atores mais centrais na rede e os recursos informacionais utilizados por estes atores. Os resultados obtidos indicam que o uso da informação na rede ocorre no âmbito tanto formal quanto informal. As fontes de informação, elo entre a informação e a rede, provêem informações ao receptor, que dela necessita. Nessa rede as fontes e serviços de informação são representados pelo Portal de Periódicos da Capes, Internet, bibliotecas, associações, sendo portanto estes os grandes facilitadores dos canais informacionais na rede.

\section{Palavras-Chave:}

Recursos informacionais; Análise de redes sociais; Centralidade de grau; Gestão da informação

\section{THE SOCIAL NETWORKS AND THE USE OF INFORMATION AMONG UEL'S RESEARCHERS OF FUNCTIONAL FOODS.}

\begin{abstract}
:
Networks are developed through the contacts established by its actors, provoke the social construction of the individual, and, when seen through its relations, can identify cohesions and similarities, in coadunated activities of individuals who act as a single social body. Studying information use within Universidade Estadual de Londrina (UEL) functional food's network and its resources was the main goal of this work. The studied network is characterized by a group of researchers who seeks the development of this specialty - functional foods. Through Social Network Analysis' (SNA) methodology, the central actors in the network and the informational resources used by such actors were identified. The results indicate that the use of information within the network occurs either in the formal scope and in the informal scope. The information resources, the link between information and network, provide information to the receptor, who needs it. In such network, the resources and information services are represented by Capes' Periodicals Portal, Internet, libraries, and associations, which could be said, then, as the great facilitators of informational channels in the network.
\end{abstract}

\section{Keywords:}

Informational resources; Social networks analysis; Degree centrality; Information management 


\section{INTRODUÇÃO}

As organizações precisam estar em sintonia com os processos informacionais e tecnológicos que a sociedade em rede exige, para isso é importante que identifiquem fluxos, processem e disseminem informações de diversas fontes e em diferentes contextos.

Os fluxos de informação que permeiam uma determinada comunidade científica revelam relações e parcerias anteriormente invisíveis, mas que podem assumir um papel de grande importância para o desenvolvimento e projeção de tal rede.

Ao se identificarem os canais de comunicação existentes em uma rede pode ocorrer uma maximização do uso dos fluxos de informação, fato este que contribui para a promoção e fortalecimento de programas, ações e recursos que consolidem a pesquisa e o desenvolvimento (P\&D) em uma área, proporcionando assim uma maior articulação e cooperação entre os membros da rede. É importante que esses programas, ações e recursos estejam vinculados à gestão da informação, que tem como característica determinante o emprego e utilização da informação com maior propriedade e aproveitamento.

Razão porque, o papel de um gestor da informação é fundamental para maximizar o uso dos serviços e produtos agregados aos canais de comunicação de uma área ou de uma organização. A função do gestor da informação consiste em receber, tratar e posteriormente disseminar a informação a indivíduos que a demandem, antes mesmo que este tenha consciência que irá necessitar de tal informação. Uma boa infra-estrutura informacional respalda a elaboração de projetos e auxilia na solução de problemas, gerando novos conhecimentos. Sendo assim, para desenvolver uma eficaz gestão da informação em uma organização, é preciso condições de trabalho, com meios adequados para buscar, organizar, recuperar e disseminar informações, que, quando bem gerenciadas e trabalhadas, podem levar uma organização ou uma comunidade a obter vantagens competitivas, e, ainda, à criação e ao desenvolvimento de novos canais para enfrentar a concorrência, ou manter-se na liderança.

A identificação dos vários tipos de informações utilizadas e das relações existentes entre os membros de uma rede pode ser útil para proporcionar uma eficiente gestão da 
informação, evitando-se com isso, a perda de informações relevantes que possam vir a gerar conhecimento.

Conhecer os principais atores de uma rede, os tipos de informações que são utilizados e gerados por estes atores e quem são as pessoas que utilizam essas informações, possibilita criar novas oportunidades, que podem alavancar o desenvolvimento da área.

Dentro desta acepção é que este estudo pesquisou a rede de alimentos funcionais da Universidade Estadual de Londrina (UEL), procurando com seu mapeamento distinguir os canais de comunicação e a tipologia dos fluxos informacionais que são realmente importantes e necessários para agregar valor à rede.

O objetivo deste trabalho, identificar o uso da informação na rede de alimentos funcionais da UEL, pode ser alcançado por meio do mapeamento da rede, pela distinção dos atores mais centrais e pelo levantamento dos recursos informacionais utilizados por estes atores.

O conhecimento dos canais de comunicação e do posicionamento de um ator em uma rede pode contribuir para um melhor aproveitamento dos fluxos de informação nela contidos, visto serem as redes sociais caracterizadas por um conjunto de interações entre indivíduos e, por meio destas interações, poderem-se distinguir padrões de relacionamento entre seus membros.

\section{PROCEDIMENTOS METODOLÓGICOS}

Alimentos funcionais são considerados "todos aqueles alimentos ou ingredientes que, além das funções nutricionais básicas, [...] produzem efeitos metabólicos e/ou fisiológicos e/ou efeitos benéficos à saúde" (BRASIL, 1999). Ou seja, são alimentos que contribuem para a saúde das pessoas, ainda que não tenham propriedades que atuem na cura de doenças. Esses alimentos causam benefícios à saúde pela prevenção ou retardamento de doenças.

Na UEL a pesquisa em alimentos funcionais conta com professores/pesquisadores de diversos departamentos - Biologia Geral; Patologia; Zootecnia; Agronomia; Bioquímica e Biotecnologia; Análises Clínicas; Química; Farmácia. O departamento que mais têm profissionais envolvidos com esta especialidade é o Departamento de Tecnologia de Alimentos e Medicamentos (TAM), que foi criado em 1977 e é constituído por cerca de 20 docentes que desenvolvem, também, atividades didáticas nos cursos de Farmácia, 
Agronomia, Zootecnia, Medicina Veterinária e Enfermagem. O departamento ainda oferece os cursos de Mestrado e Doutorado em Ciência de Alimentos e mantém um curso de especialização em Gestão da Qualidade de Alimentos.

O Programa de Pós-graduação em Ciência de Alimentos da UEL é o maior responsável pelo fortalecimento do corpo de pesquisadores e pelas pesquisas na especialidade de alimentos funcionais. Os cursos de pós-graduação deste programa são pioneiros na Universidade.

A metodologia adotada, neste trabalho, foi a Análise de Redes Sociais (ARS), que permite a identificação dos canais de comunicação de uma população por meio de suas relações. No estudo da ARS, o foco principal são as relações entre os atores de uma determinada comunidade, ou seja, as relações entre atores se tornam prioridade, as propriedades individuais são secundárias e os dados relacionais são o núcleo das investigações (HAYTHORNTHWAITE, 1996; OTTE; ROUSSEAU, 2002).

Os conceitos fundamentais em ARS são: atores, atributos, ligação relacional e relação. Um ator é a representação de um membro da rede, que pode ser um indivíduo ou um conjunto de indivíduos. Os atributos de um ator são suas características próprias, e a ligação relacional, também chamada de laço relacional, é o vínculo existente em uma relação entre dois atores (HANNEMAN, 2001).

A população estudada nesta pesquisa são os 39 pesquisadores em alimentos funcionais oriundos da UEL, aqui denominados de atores.

A coleta de dados para esta pesquisa foi feita por meio de um questionário, elaborado e aplicado pelos coordenadores da Rede de Cooperação e Inovação em Alimentos Funcionais do Estado do Paraná, rede esta constituída por um grupo de especialistas, vinculados aos setores acadêmico, científico e produtivo, trabalhando em conjunto, em prol do fortalecimento de programas, ações e recursos, que consolidem a P\&D na área de Alimentos Funcionais no Estado do Paraná.

Para a consecução dos propósitos deste estudo, utilizou-se parte deste questionário. A primeira parte analisada do questionário referia-se às ligações entre os pesquisadores, na 
qual eles indicaram os pares - internos ou externos à instituição - com os quais mantinham contatos mais intensos, naquele momento, fornecendo ou recebendo informações. E a segunda parte abordou os tipos de informação que os pesquisadores julgavam importantes para a realização de seu trabalho e as fontes em que as localizavam, podendo indicar vários tipos de informação dentro de uma série de opções preestabelecidas.

Na primeira parte analisada, que deu subsídio para o mapeamento da rede, foram considerados somente os atores citados que pertenciam a UEL, e que tinham respondido ao questionário.

Para o mapeamento da rede, foi utilizado o software Ucinet, que configura e identifica os padrões de relacionamentos da rede, bem como possibilita a visualização da posição/papel dos atores (BORGATTI; EVERETT; FREEMAN, 2002).

Com base nas indicações dos pesquisadores e no mapeamento da rede da UEL calculouse a medida de centralidade de grau, pertinente à ARS, medida esta que identifica os atores mais importantes na rede. A partir da identificação desses atores mais centrais, foram analisadas as informações pertinentes aos recursos informacionais utilizados, e com base nestes recursos pôde-se caracterizar o processo de gestão da informação.

\section{TIPOS E FLUXOS DE INFORMAÇÃO}

A informação para ter valor necessita ser disseminada, podendo vir a gerar conhecimento e assim contribuir para a democratização da informação, em outras palavras, disponibilizar o conhecimento adquirido na sociedade na qual o indivíduo esteja inserido (BARRETO, 1994).

De acordo com Ponjuán Dante (2004), a informação está sujeita a dados que se convertam em informação e tenham um significado a partir de diferentes processos de agregação de valor, e uma determinada significação. E o conhecimento é a informação transformada em crenças, conceitos e modelos mentais, mediante raciocínios e reflexões.

Assim como a informação, o conhecimento vem sofrendo várias mudanças na sociedade e no ambiente organizacional, aumentando significativamente sua importância. Nonaka e 
Takeuchi (1992) apontam semelhanças e diferenças entre eles, quando dizem que o conhecimento está vinculado a crenças, valores, ações, e em comum com a informação eles destacam o significado e sua vinculação às relações mantidas pelos indivíduos.

Pode-se dizer que o bom uso da informação e sua aplicabilidade no momento oportuno têm como resultado final a geração do conhecimento. Também para a formulação de uma eficaz e eficiente ação ou programa que possa subsidiar os processos de inovação em uma organização o insumo básico compreende a informação e o conhecimento, ou seja, ao usar a informação adequadamente, as organizações têm grandes chances de conseguir bons resultados, que podem manifestar-se por meio de parcerias e cooperações estratégicas no mercado competitivo (BARRETO ET AL., 1997).

É possível distinguir vários tipos de informação, que interferem no processo de desenvolvimento científico, tecnológico, industrial, econômico e social. Aguiar (1991) identificou e caracterizou os objetivos e funções de diferentes tipos de informação, que para uma melhor visualização foram compiladas e apresentadas no quadro 1.

\begin{tabular}{|c|c|c|}
\hline $\begin{array}{l}\text { TIPO } \\
\text { INFORMAÇÃO }\end{array}$ & CONCEITO & OBJETIVOS E FUNÇÕES \\
\hline \multirow[b]{3}{*}{$\begin{array}{l}\text { Informação } \\
\text { Científica }\end{array}$} & \multirow{3}{*}{$\begin{array}{l}\text { Todo } \\
\text { conhecimento } \\
\text { que esteja } \\
\text { relacionada ou } \\
\text { resulte em uma } \\
\text { pesquisa } \\
\text { científica }\end{array}$} & Divulgação do conhecimento \\
\hline & & Evolução da ciência \\
\hline & & $\begin{array}{l}\text { Explicação da metodologia usada } \\
\text { na pesquisa }\end{array}$ \\
\hline \multirow{6}{*}{$\begin{array}{l}\text { Informação } \\
\text { Tecnológica }\end{array}$} & \multirow{6}{*}{$\begin{array}{l}\text { Todo tipo de } \\
\text { conhecimento } \\
\text { relacionado com } \\
\text { o modo de gerar } \\
\text { um produto ou } \\
\text { com a prestação } \\
\text { de um serviço }\end{array}$} & $\begin{array}{l}\text { Insumo para o desenvolvimento } \\
\text { de pesquisas tecnológicas }\end{array}$ \\
\hline & & $\begin{array}{l}\text { Segurança do direito de } \\
\text { propriedade intelectual }\end{array}$ \\
\hline & & $\begin{array}{l}\text { Contribuição a publicações } \\
\text { sobre pesquisas tecnológicas }\end{array}$ \\
\hline & & $\begin{array}{l}\text { Subsídio ao processo de gestão } \\
\text { tecnológica }\end{array}$ \\
\hline & & $\begin{array}{l}\text { Avaliação e acompanhamento de } \\
\text { novas tendências tecnológicas }\end{array}$ \\
\hline & & $\begin{array}{l}\text { Avaliação do impacto econômico, } \\
\text { social e ambiental da tecnologia }\end{array}$ \\
\hline
\end{tabular}

(c) Revista Digital de Biblioteconomia e Ciência da Informação,Campinas, v.6, n.1, p. 15-37, jul/dez. 2008 - ISSN: 1678-765X. 


\begin{tabular}{|c|c|c|}
\hline \multirow{3}{*}{$\begin{array}{l}\text { Informação em } \\
\text { C\&T }\end{array}$} & & $\begin{array}{l}\text { Mesmas funções das informações } \\
\text { científicas e tecnológicas }\end{array}$ \\
\hline & & Divulgar centros de pesquisa \\
\hline & & $\begin{array}{l}\text { Divulgar pesquisas em andamento } \\
\text { ou já encerradas }\end{array}$ \\
\hline \multirow{7}{*}{$\begin{array}{l}\text { Informação } \\
\text { para Indústria }\end{array}$} & \multirow{7}{*}{$\begin{array}{l}\text { Conjunto de } \\
\text { informações que } \\
\text { uma empresa } \\
\text { necessita. }\end{array}$} & Fornecer informações sobre: \\
\hline & & Regulamentos \\
\hline & & Planejamentos operacionais \\
\hline & & Leis trabalhistas \\
\hline & & Obrigações fiscais e comerciais \\
\hline & & Tendências de mercado \\
\hline & & Processo decisório \\
\hline \multirow{2}{*}{$\begin{array}{l}\text { Informação } \\
\text { Industrial }\end{array}$} & \multirow{2}{*}{$\begin{array}{l}\text { Fornece subsídio } \\
\text { para comparação } \\
\text { do desempenho } \\
\text { industrial em } \\
\text { âmbito nacional } \\
\text { e internacional. }\end{array}$} & $\begin{array}{lrr}\text { Formular } & \text { processos } & \text { públicos e } \\
\text { privados } & \text { para } & \text { análises } \\
\text { socioeconômicas } & \end{array}$ \\
\hline & & $\begin{array}{l}\text { Identificar problemas típicos do } \\
\text { setor industrial. }\end{array}$ \\
\hline
\end{tabular}

Quadro 1 - Tipos de Informação.

Pode-se observar, no quadro 1, que as informações científicas, tecnológicas e em C\&T estão relacionadas: à evolução da ciência; a disseminação do conhecimento, seja por meio de publicações científicas seja pela geração de novos produtos ou serviços; divulgação de centros e institutos de pesquisa; a identificação, avaliação e acompanhamento dos impactos econômicos, sociais e ambientais da tecnologia. Enquanto as informações para a indústria e as informações industriais estão diretamente vinculadas a negócios, ou seja, ao fornecimento de informações úteis para o bom funcionamento de uma empresa, tanto em âmbito nacional como internacional, e à identificação, formulação e resolução de problemas de ordem operacional, administrativa, comercial e financeira.

Pelos argumentos que descrevem os tipos de informação denota-se que as interações as fazem evoluir, situação retratada por Barreto (1998) quando afirma que a necessidade de exercer o processo de comunicação é inerente ao ser humano, isto é, compartilham informações, o que aumenta substancialmente os fluxos de informação e os canais de comunicação. O autor ainda explica que devido às grandes quantidades de informação que estão sendo geradas e transmitidas, é necessária a adoção de ferramentas específicas, 
para assim poder compactar, utilizar e recuperar estas informações com maior facilidade e êxito, ocorrendo, portanto, certa diminuição no uso das linguagens naturais e a adoção de novos processos de linguagem de hipermídia, que aumentam o poder de assimilação da informação pelos receptores.

Assimilar todos os tipos de informações que fluem nos canais comunicacionais torna-se uma tarefa impossível, mas o maior desafio ainda é a seleção e a disponibilização de informações pertinentes e úteis para o melhor desenvolvimento da organização em que se esteja inserido.

Ponjuán Dante (2004) destaca três tipos de fontes informacionais, as fontes documentais, pessoais e institucionais. Montalli e Campello (1997) também apresentam três distintos tipos de fontes de informação, as fontes técnica, para negócios e científica. Estas fontes de informação são objetos para geração, processamento, disseminação e compartilhamento da informação. As fontes propostas pelas autoras foram organizadas no quadro 2.

\begin{tabular}{|l|l|}
\hline Ponjuán Dante & Montalli e Campello \\
\hline $\begin{array}{l}\text { Fontes Documentais - planos de } \\
\text { trabalho, informes financeiros, faturas, } \\
\text { livros, documentos oficiais, entre } \\
\text { outros documentos; }\end{array}$ & $\begin{array}{l}\text { Fontes de Informação Técnica - } \\
\text { normas técnicas, patentes, legislação, } \\
\text { publicações oficiais referentes à área. }\end{array}$ \\
\hline $\begin{array}{l}\text { Fontes Pessoais - consultores, } \\
\text { bibliotecários, pesquisadores, analistas; }\end{array}$ & $\begin{array}{l}\text { Fontes de Informação para Negócios - } \\
\text { relatórios referentes a companhias, } \\
\text { relatórios sobre pesquisas de mercado, } \\
\text { manuais, guias, publicações estatísticas. }\end{array}$ \\
\hline $\begin{array}{l}\text { Fontes Institucionais - bibliotecas, } \\
\text { arquivos, meios de comunicação, } \\
\text { instituições financeiras, associações } \\
\text { profissionais. }\end{array}$ & $\begin{array}{l}\text { Fontes de Informação Científica - } \\
\text { monografias, dissertações, } \\
\text { periódicos científicos, anais de eventos } \\
\text { científicos. }\end{array}$ \\
\hline
\end{tabular}

Quadro 2 - Fontes de Informação.

Analisando as informações apresentadas no quadro 2, observa-se que as fontes de informação propostas por Ponjuán Dante (2004) podem ser diferenciadas facilmente umas das outras, visto que as fontes documentais estão diretamente ligadas a documentos, sejam estes de ordem científica, financeira, administrativa ou comercial; as fontes 
pessoais são caracterizadas pelos agentes que se utilizam das informações documentais; e as fontes institucionais são formadas pelas organizações que propiciam a geração, a disseminação e a recuperação das informações geradas, enquanto as fontes propostas por Montalli e Campello (1997) estão totalmente ligadas a informações registradas, sejam elas normas, patentes, legislações, relatórios, periódicos, livros, entre outros tipos de materiais, e são caracterizadas por serem disseminadas pelos canais formais de comunicação. Pode-se deduzir que estes três tipos de fontes informacionais - técnica, para negócio e científica - são originários das fontes documentais categorizadas por Ponjuán Dante.

Ainda em relação às fontes de informação, Ponjuán Dante (2004) explica que, de acordo com cada organização, essas fontes podem se diferenciar.

Em relação aos fluxos de informação existentes em uma empresa, Lesca e Almeida (1994) descrevem a existência de três tipos distintos, sendo eles: a) Fluxo criado internamente para o seu próprio uso (emissor e receptor interno); b) Fluxo criado internamente, mas com uso orientado para o meio externo (emissor interno, receptor externo); e c) Fluxo coletado externamente e usado internamente (emissor externo, receptor interno).

Os fluxos de informação existentes em uma organização podem ser internos ou externos. Se o fluxo for interno, quem gera a informação, no caso o emissor, está dentro da organização, sendo importante conhecê-lo para potencializar a geração de informação. E quando se tratar de um fluxo externo, também é importante conhecer o emissor da informação, o local em que foi gerada, quem a distribuiu, e quais são os elementos que podem caracterizar o valor desta fonte (PONJUÁN DANTE, 2004).

Os fluxos informacionais vêm-se transformando e modificando o ambiente organizacional no qual se encontra, ou seja, está ocorrendo uma transformação da tipologia da informação e dos canais comunicacionais, conforme salienta Barreto (1998), quando relata as mudanças que estão ocorrendo em relação à migração do suporte escrito para o eletrônico, sejam estas mudanças nas formas de busca, acesso e disseminação da informação, por meio dos canais comunicacionais.

(c) Revista Digital de Biblioteconomia e Ciência da Informação,Campinas, v.6, n.1, p. 15-37, jul/dez. 2008 - ISSN: 1678-765X. 
O autor ressalta ainda que as diferenças do compartilhamento da informação do meio tradicional para o meio eletrônico têm de ser levadas em consideração, isso em virtude do processo técnico de informação não ser o mesmo que o processo social de seu compartilhamento, visto que neste último processo são criados vários micronúcleos sociais com diferenças profundas, tais como: acesso à informação, confiança no canal de compartilhamento, tradições, costumes, entre outras.

De acordo com Araújo (1999), com o aumento do uso dos fluxos informacionais eletrônicos, que proporciona tantas mudanças no cenário organizacional, ocorre a multiplicação dos centros de pesquisas e dos meios e formas de comunicação da informação, sendo então evidenciado o surgimento de novas tecnologias de acesso à informação e por conseqüência, a promoção da comunicação e das redes sociais.

\section{REDES SOCIAIS}

Vivemos em rede: o trabalho, a família, os amigos, formam uma rede, de contatos, afetos, negócios, etc. Estamos unidos às pessoas; por sua vez, estas a outras pessoas, formando, assim, uma rede de relacionamentos.

Uma rede social consiste de um ou mais conjuntos finitos de atores [e eventos] e todas as relações definidas entre eles” (MATHEUS; SILVA, 2006, p.2). Uma rede também pode ser conceituada de uma forma simples como "um conjunto de pontos interligados [...], um agrupamento de pontos ou 'nós' que se ligam a outros pontos por meio de linhas". (COSTA; MARTINHO; FECURI, 2003, p.23).

As redes sempre estiveram presentes nas relações entre pessoas ou organizações de diversos tipos. De acordo com Watts (2004), os estudos de redes e sistemas de redes tiveram um crescimento extraordinário, nos últimos anos, nas pesquisas acadêmicas, embora na Sociologia e na Antropologia as análises de redes tenham uma longa tradição.

Estes estudos são impulsionados pela rapidez do crescimento, disponibilidade e maior acessibilidade a grandes porções de dados constantes em pesquisas e estudos nas ciências exatas, biológicas e sociais. Por meio do estudo das redes estão sendo solucionados 
problemas previamente intransponíveis, reformulando assim velhas idéias, introduzindo novas técnicas e descobrindo conexões (WATTS, 2004; KOSSINETS; WATTS, 2006).

Os estudos de redes têm contribuído para revolucionar os estudos acadêmicos, visto que, por meio destes estudos, pode-se observar e estudar o mundo em movimento, como ressaltam Molina e Aguilar (2004). Nesse mesmo sentido, Marteleto (2001) destaca que, no estudo de redes sociais, as estruturas hierárquicas não são privilegiadas, ao passo que nesse método de estudo são valorizados os elos e as relações informais entre pessoas ou organizações.

Para cada conexão em uma rede há dois nós ou pontos interligados. Um ponto pode estar interligado a vários outros pontos, sendo possível manter uma série de ligações originadas dele.

O poder da rede advém dessa propriedade de multiplicação inerente ao processo de fazer conexões, isto pelo fato de que cada linha pressupõe dois pontos e de que cada ponto pode estar na origem de uma infinidade de linhas.

Segundo Tomaél, Alcará e Di Chiara (2005), as redes sociais traduzem a representação formal de atores e suas relações, e a representação da estrutura social por meio de uma rede permite sua análise pela teoria de grafos, já que as redes sociais traduzem a representação de um ator e suas relações, e neste sentido Tomaél et al. (2005) também destacam que as redes sempre pressupõem agrupamentos, isto é, representam fenômenos coletivos e as relações mantidas pelos atores são oriundas do trabalho, da amizade, do estudo, do lazer além de outros fatores.

De acordo com Ugarte (2004), analisar redes sociais é antes de tudo determinar sua estrutura, e, por conseqüência, estabelecer os seus parâmetros possíveis de atuação, tanto dos indivíduos que formam essa rede, quanto da rede como um todo. O estudo de redes pode ser definido como um conjunto de nós que, analisados socialmente, representam os atores da rede e são unidos por ligações que representam suas relações. 


\section{REDES SOCIAIS DOS PESQUISADORES EM ALIMENTOS FUNCIONAIS DA}

UEL

A centralidade de grau - degree centrality - é definida por Otte e Rousseau (2002) como a quantidade de ligações que um ator possui, sejam estas ligações emitidas ou recebidas. Nesse sentido, Hanneman (2001) esclarece que, quando um ator dispõe de muitas ligações, ele pode-se beneficiar desta posição logo que, ao possuir várias alternativas e formas de se relacionar, poderá ser menos dependente do que os outros indivíduos e ter maior acesso aos fluxos de informação, permitindo um maior compartilhamento da informação.

Com o cálculo da medida de centralidade de grau obtém-se o índice de entrada e o índice de saída. O valor do índice de entrada de um ator pode indicar que este ator seja proeminente e prestigiado pelos outros indivíduos da rede, visto que muitos buscam manter ligações com ele; e o valor do índice de saída pode indicar a alta capacidade de comunicação e influência deste ator. Logo, ao indicar muitos atores, ele estará mantendo os outros informados de seu ponto de vista (HANNEMAN, 2001; MARTELETO, 2001).

Quando um ator se encontra em uma posição privilegiada de comunicação com outros atores, ele deveria ser visto por estes como o principal canal de comunicação, visto que, sendo este um ponto crucial de comunicação, ao menos em relação as suas ligações diretas, ele poderá ser o desencadeador de um senso de liderança nos fluxos de informação (FREEMAN, 1979).

Com base no índice de entrada, obtido por meio da centralidade de grau, foram identificados os atores que obtiveram um índice igual ou superior a três, ou seja, os que foram indicados no mínimo por três outros atores. Com base neste critério, destacaram-se 13 atores que foram considerados como os mais proeminentes na rede em relação ao grau, conforme se pode observar no quadro 3, em que os atores estão identificados por duas letras.

Portanto, ao calcular a medida de centralidade de grau, revelam-se, por meio do índice de saída, quantos indivíduos o ator citou e, por meio do índice de entrada, sendo este o mais importante, quantas vezes o ator foi indicado pelos outros. O ator BM foi o mais proeminente, de acordo com a medida de centralidade de grau. 


\begin{tabular}{|l|l|l|}
\hline ATOR & $\begin{array}{l}\text { ÍNDICE } \\
\text { ENTRADA }\end{array}$ & $\begin{array}{l}\text { ÍNDICE } \\
\text { SAÍDA }\end{array}$ \\
\hline BM & 10 & 6 \\
\hline AM & 6 & 4 \\
\hline AZ & 5 & 4 \\
\hline BK & 5 & 2 \\
\hline BI & 5 & 2 \\
\hline AX & 5 & 1 \\
\hline AA & 4 & 4 \\
\hline BJ & 4 & 3 \\
\hline BH & 4 & 1 \\
\hline AT & 3 & 3 \\
\hline AQ & 3 & 3 \\
\hline AR & 3 & 2 \\
\hline BA & 3 & 1 \\
\hline
\end{tabular}

Quadro 3 - Centralidade de Grau.

A figura 1 apresenta a rede dos atores em alimentos funcionais da UEL. Na forma de quadrado estão representados os 13 atores mais centrais, e na forma de círculo os outros 26 atores, que não obtiveram índices significativos - mais do que três indicações dos outros membros da rede.

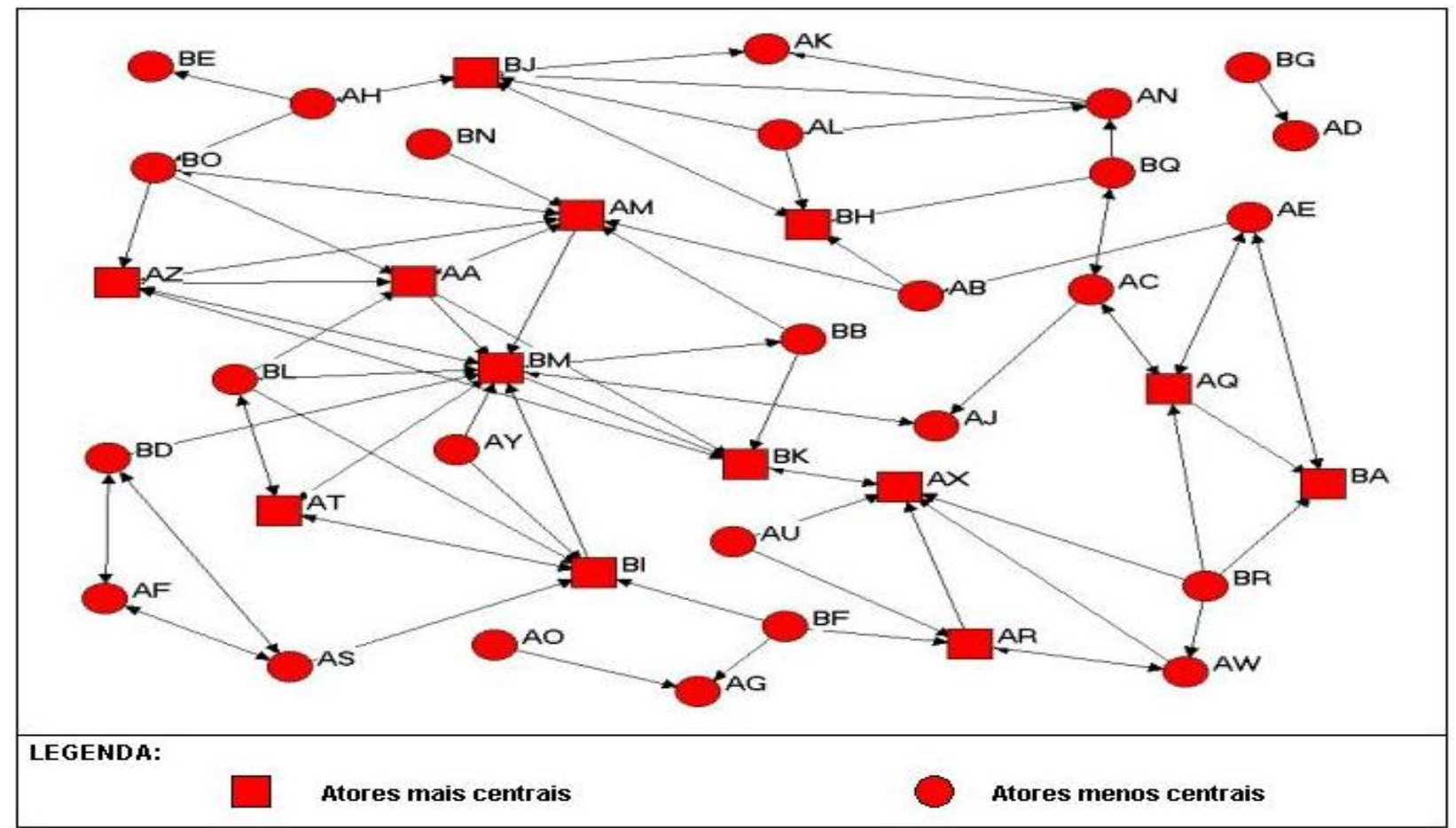

Figura 1 - Rede de Alimentos Funcionais da UEL 
Dos 13 atores mais centrais na rede, sete são do gênero masculino, o que evidencia que na Rede de Alimentos Funcionais da UEL, existe certa heterogeneidade, ao menos entre os atores mais centrais. Observa-se também que, destes atores mais centrais, todos possuem doutorado e sete destes também são pós-doutores na área de Ciência e Tecnologia de Alimentos e os outros seis em áreas correlatas.

Os atores mais centrais são os mais proeminentes, visto que receberam pelo menos três indicações dos outros atores da rede. $\mathrm{O}$ ator - BM - foi identificado como o mais central, por ter sido indicado por outros dez atores, e seu índice de saída na rede também é considerado como o mais alto entre os atores; portanto, este ator provavelmente é o mais importante na rede e também o mais influente, e mantém um canal de comunicação direto com mais seis atores.

\section{RECURSOS INFORMACIONAIS}

Com base na análise dos tipos de informações mais importantes para os atores centrais na realização de seus trabalhos, e a fonte que as localiza, podem-se distinguir quais os recursos informacionais utilizados por estes atores. Cabe ressaltar que foram focos da análise os recursos informacionais citados pelos atores que obtiveram três ou mais indicações por outros atores da rede, perfazendo um total de 13 atores.

Os recursos informacionais analisados estão apresentados, a seguir, em ordem de importância de acordo com a quantidade de indicações. Os mais utilizados são: literatura científica; eventos científicos; pesquisas e pesquisadores; normas técnicas, legislações e regulamentações; associações de classe; patentes.

- Literatura científica

Os 13 atores analisados indicaram a literatura científica como um tipo de informação importante para a realização de seus trabalhos. A literatura científica, neste caso, é representada por livros, periódicos e outros documentos. Pode-se inferir que a maior ênfase está nos periódicos, visto que muitos atores indicaram o Portal de Periódicos da Capes como uma fonte de informação útil. Esse resultado confirma o que ressalta Mueller (2003) quando diz que os periódicos, quer impressos, quer seja eletrônicos, constituem o maior canal de comunicação entre os cientistas.

- Eventos científicos 
Cerca de 10 atores consideram importantes as informações provenientes de eventos científicos, sejam eles na área de Ciência e Tecnologia de Alimentos sejam em áreas correlatas, já que se acredita que, ao participar de um evento, podem-se conhecer pessoas e aumentar a rede de contatos, além de ser possível receber informações sobre novos trabalhos na área. O principal evento da área, no Brasil, é o Congresso Brasileiro de Ciência e Tecnologia de Alimentos.

Campello (2003a) diz que, por meio da apresentação de trabalhos, o pesquisador tem seu trabalho avaliado pelos pares, de uma forma mais ampla, diferentemente do que ocorre, quando um trabalho é submetido a um periódico científico, que é avaliado por uma comissão editorial restrita.

- Pesquisas e pesquisadores

Ao todo nove atores indicaram a importância das informações sobre pesquisas e pesquisadores da área, sejam estas informações sobre o ambiente interno, sejam sobre o ambiente externo ao da instituição. Pode-se observar que os atores procuram cada vez mais informações sobre os pesquisadores da área e suas linhas de pesquisa. Parecem que estão interessados em informações que dêem subsídios à geração de contatos, que podem vir a gerar parcerias e colaborações, para novos trabalhos, ou mesmo resolver problemas que possam encontrar no decorrer de suas pesquisas.

A Plataforma Lattes do CNPq é a principal fonte de informação para consulta a pesquisadores e suas pesquisas. Campello (2003c) e Araújo (1999) advertem que a divulgação de informações sobre pesquisas e pesquisadores por meio dos canais formais de comunicação - livros, periódicos - tem-se tornado obsoletos, pela sua demora e dificuldade de publicação, passando os fluxos informacionais eletrônicos a assumir um papel alternativo na divulgação de pesquisas e pesquisadores nos canais de comunicação.

- Normas técnicas, legislações e regulamentações

Oito atores indicaram as informações provenientes de normas técnicas, legislações e regulamentações como importantes. Mas a maioria dos atores salientou certa dificuldade em encontrar e adquirir tais normas, pelo seu alto custo. Alguns atores citaram a Agência Nacional de Vigilância Sanitária (ANVISA) e Agências Reguladoras Nacionais e Internacionais.

A grande exigência referente à normalização de produtos e serviços e a necessidade de competitividade tanto no mercado nacional quanto no internacional vêm exigindo especificações de alto padrão tecnológico, políticas de normalização e informações

(c) Revista Digital de Biblioteconomia e Ciência da Informação,Campinas, v.6, n.1, p. 15-37, jul/dez. 2008 - ISSN: 1678-765X. 
precisas sobre fornecedores, matérias-primas, produção de produtos, que poderão ser colocados no mercado ou mesmo que já estejam sendo comercializados (DIAS, 2003).

- Associações de classe

As associações de classe foram indicadas por sete atores, como uma importante fonte de informação, corroborando a constatação de Campello (2003b), para quem as associações são importantes fontes de informação, e o acesso às estas informações se dão por meio de documentos gerados por elas e pelos indivíduos ligados a elas. A Sociedade Brasileira de Ciência e Tecnologia de Alimentos (SBCTA) foi a associação mais citada pelos atores.

- Patentes $^{1}$

Seis atores indicaram a patente como uma importante fonte de informação para a realização de seus trabalhos. Pode-se inferir que as patentes assumem uma importante função de fonte de informação, visto que a elas é conferido o título de mais importante fonte de informação tecnológica, mas sabe-se que raramente são utilizadas na busca por informações (FRANÇA, 2003).

\section{INFORMAÇÃO E REDES}

Cada vez mais as organizações buscam o trabalho em rede, pois, ao se trabalhar desta forma, pode-se conseguir um maior número de parcerias e cooperações, gerando-se assim um maior fortalecimento da rede, ou ainda criando-se parcerias que poderão desencadear novas redes e, assim, uma maior geração e troca de informações e conhecimentos que poderão vir a subsidiar os processos de inovação.

Vale lembrar que, no trabalho em rede, um fator importante é o conhecimento de seus membros, visto que, ao se saber qual a posição dos atores entre os canais de comunicação, poder-se-á vir revelada a capacidade de comunicação e influência, conforme afirmam Hanneman (2001) e Marteleto (2001), uma vez que, ao estar presente em muitos canais de comunicação, um ator poderá controlar os fluxos de informação contidos na rede.

Observa-se que na rede de alimentos funcionais da UEL os atores indicaram a literatura científica como a mais importante fonte de informação, mas também atribuem importância a outras fontes, o que pode ser comprovado ao observar-se que os atores 
proeminentes da rede acreditam que as informações originárias de eventos científicos podem ser também fontes de informação valorosas, fato esse que evidencia a afirmação de Marteleto (2001), quando destaca que as redes sociais buscam desvendar os canais de comunicação informais, ou seja, as relações não são hierarquizadas e, portanto, ao se participar de um congresso, podem-se conhecer pessoas, trocar experiências, compartilhar conhecimento, e ainda, como destaca Tomaél et al. (2005), podem-se criar novas relações que serão, neste caso, oriundas do trabalho e estudo. Essas relações serão, por sua vez, pontes para novas outras que formarão novas redes de contatos ou mesmo fortalecerão a rede existente.

Este fato pode ser retomado, com base na afirmação de Barreto (1998) e Ponjuán Dante (2004), o primeiro dizendo que o ser humano necessita comunicar-se, seja por qualquer canal de comunicação, formal ou informal, mas vale lembrar que ao disseminar uma informação deve-se levar em conta o emissor desta mensagem, que, de acordo com o segundo autor, se for interno deve ser potencializado, e, se externo, é necessário que se caracterizem os valores que formam esta fonte.

Outra fonte evidentemente importante na rede são as informações sobre pesquisas e pesquisadores a vista disso, percebe-se que as comunidades científicas aparecem cada vez mais organizadas, ocorrendo então uma maior disseminação das informações geradas pelos seus membros e sendo estas informações de grande valor para os membros da rede estudada, visto que, ao se saber quais os assuntos das pesquisas e quem são os pesquisadores mais notórios da área, poderá haver um maior compartilhamento de informações, gerando-se assim uma rede de contatos entre estes profissionais, e os resultados estão em sintonia com as afirmações de Ponjuán Dante (2004), quando se refere à importância das fontes pessoais de informação.

Outro ponto que pode ser destacado, de acordo com Barreto (1998) e Araújo (1999), é a maior facilidade de acesso a estas informações. Devido a grande massa de informações geradas, criaram-se ferramentas capazes de agilizar o compartilhamento da informação, pelos mais diversos fluxos, vindo os fluxos de informação eletrônicos, como, por

\footnotetext{
1 “A patente é o instrumento legal destinado a proteger a invenção aplicável a indústria, durante um prazo de tempo definido, contra cópias e quaisquer outros usos não autorizados pelo seu possuidor, de modo a permiti-lhe a exploração rentável dessa nova idéia” (FRANÇA, 2003, p.153).
} 
exemplo, a Internet, a proporcionar uma maior interação entre as mais diversas comunidades e uma multiplicação de centros de pesquisa.

Barreto (1994) lembra, ainda que, com uma maior facilidade de comunicação entre diversos atores, ocorre certa democratização da informação e disponibilização do conhecimento, ao menos entre os membros de duas ou mais redes que anteriormente tinham uma maior dificuldade de comunicação. Portanto, devido à agilidade de busca, acesso e uso de informações, e também do aumento do trabalho em rede, existe maior facilidade de resolução de problemas, anteriormente intransponíveis (WATTS, 2004).

Pela dificuldade de localização de informações em fontes, como as normas técnicas, as regulamentações é uma constante na rede e, para que ocorra uma maior facilidade de busca, uso, geração e disseminação de informações úteis, torna-se necessário a criação e implantação de uma eficiente política informacional. Para que essa política informacional produza o resultado esperado, as organizações buscam sempre mais parcerias, ou seja, o trabalho em rede, tendo como insumo básico para a inovação a informação e o conhecimento (BARRETO ET AL., 1997).

\section{CONSIDERAÇÕES FINAIS}

Em se tratando da economia baseada no conhecimento, a geração e o compartilhamento de informações e conhecimentos, que poderão vir a gerar inovações, tendem a fortalecer e aumentar o trabalho em rede, bem como maximizar a utilização e geração de novos fluxos de informação e de conhecimento entre os atores participantes.

A maximização das dinâmicas nos fluxos de informação, ou seja, a diversidade de fluxos existentes, bem como a qualidade das informações transmitidas, que poderão subsidiar a geração de novos conhecimentos, é considerada um dos principais fatores que embasam o progresso tecnológico, e também o pilar de sustentação econômica de uma determinada área tecnológica, de uma organização ou mesmo de uma nação.

A grande demanda de informações de caráter científico ou tecnológico, para uma maior geração ou melhoramento de invenções, é intensificada na P\&D. Neste caso, observa-se que a maioria das informações julgadas importantes para os atores mais centrais na rede é

(c) Revista Digital de Biblioteconomia e Ciência da Informação,Campinas, v.6, n.1, p. 15-37, jul/dez. 2008 - ISSN: 1678-765X. 
de caráter científico, ou seja, resultam de pesquisas científicas ou estão a elas relacionadas. Conclui-se que a literatura científica, além de divulgar a ciência, serve para os pesquisadores como um fator de validação de seus trabalhos. Em suma, quando o conhecimento científico se torna público e validado, ele poderá servir de base para a geração de outros.

Na rede estudada, as fontes informacionais documentais são as mais utilizadas provavelmente por serem um instrumento de geração do conhecimento que tem maior respaldo científico e por serem de mais fácil acesso. As fontes informacionais pessoais podem ser descritas pelos contatos informais realizados, durante eventos, ou mesmo, o contato direto do dia-a-dia entre pesquisadores. Entre as de menor uso, mas que exercem um papel fundamental na rede, encontram-se as fontes informacionais institucionais, nas quais as informações são disseminadas por meio das associações de classe, órgãos governamentais e agências reguladoras.

Pode-se inferir que os fluxos informacionais eletrônicos têm grande ênfase na rede, uma vez que a maioria dos atores destacou a Internet como a grande ferramenta de busca e obtenção das informações.

Conclui-se, com base nos resultados obtidos, que o processo de gestão da informação, não ocorre na rede em si, mas nos serviços de informação que subsidiam a rede, devido ao fato de os serviços de informação serem o elo entre a informação e a rede, por proverem de informação o receptor que dela necessita.

Na rede de alimentos funcionais da UEL, o uso de informação, ou seja, o elo entre a informação e a rede, é representado por fontes de informação como: Portal de Periódicos da Capes, Internet, Sistema de Bibliotecas da UEL, associações de classe, órgãos governamentais, agências reguladoras, sendo esses, portanto, os grandes facilitadores dos canais informacionais na rede.

A rede formada entre os pesquisadores de alimentos funcionais da UEL dissemina, entre seus membros, as fontes de informações formais que são comuns para a maioria dos seus atores. Por outro lado, o fluxo de informação informal na rede aproxima os pares, intensifica o compartilhamento da informação e fortalece as parcerias entre os pesquisadores.

(c) Revista Digital de Biblioteconomia e Ciência da Informação,Campinas, v.6, n.1, p. 15-37, jul/dez. 2008 - ISSN: 1678-765X. 


\section{REFERÊNCIAS}

AGUIAR, A.C. Informação e atividades de desenvolvimento científico, tecnológico e industrial: tipologia proposta com base em análise funcional. Ciência da Informação, Brasília, v.20, n.1, p.7-15, jan./jun. 1991.

ARAÚJO, E.A. de. Informação, sociedade e cidadania: gestão da informação no contexto de organizações não governamentais (ONGs) brasileiras. Ciência da Informação, Brasília, v.28, n.2, p.155-167, maio/ago. 1999.

BARRETO, A. de A. Mudança estrutural no fluxo do conhecimento: a comunicação eletrônica. Ciência da Informação, Brasília, v.27, n.2, p.122-127, maio/ago. 1998.

BARreto, A. de A. A questão da informação. São Paulo em Perspectiva, São Paulo, v.8, n.4, p.3-8, out./dez. 1994.

BARRETO, A.R. et al. Manual de gestão de serviços de informação. Curitiba: TECPAR; Brasília: IBICT, 1997.

BORGATTI, S.P.; EVERETT, M.G.; FREEMAN, L.C. Ucinet for Windows: software for social network analysis. Harvard: Analytic Technologies, 2002. Disponível em: <http://www.analytictech.com> Acesso em: 28 abr. 2005.

BRASIL. Portaria n³98, de 30 de abril de 1999. Diário Oficial da União, Poder Executivo, Brasília, DF, 3 maio 1999.

CAMPELLO, B.S. Encontros científicos. In.: CAMPELLO, B.S.; CENDÓN, B.V.; KREMER, J.M.(Orgs.) Fontes de informação para pesquisadores e profissionais. Belo Horizonte: Ed. UFMG, 2003a. Cap.4, p.55-72.

CAMPELLO, B.S. Organizações como fonte de informação. In.: CAMPELLO, B.S.; CENDÓN, B.V.; KREMER, J.M.(Orgs.) Fontes de informação para pesquisadores e profissionais. Belo Horizonte: Ed. UFMG, 2003b. Cap.2, p.35-48. 
CAMPELLO, B.S. Pesquisas em andamento. In.: CAMPELLO, B.S.; CENDÓN, B.V.; KREMER, J.M.(Orgs.) Fontes de informação para pesquisadores e profissionais. Belo Horizonte: Ed. UFMG, 2003c. Cap.3, p.49-54.

COSTA, L.; MARTINHO, C.; FECURI, J.(Coords.). Redes: uma introdução às dinâmicas da conectividade e da auto-organização. Brasília: WWF-Brasil, 2003.

DIAS, M.M.K. Normas técnicas. In.: CAMPELLO, B.S.; CENDÓN, B.V.; KREMER, J.M.(Orgs.) Fontes de informação para pesquisadores e profissionais. Belo Horizonte: Ed. UFMG, 2003. Cap.11, p.137-152.

FRANÇA, R.O. A patente. In.: CAMPELLO, B.S.; CENDÓN, B.V.; KREMER, J.M.(Orgs.) Fontes de informação para pesquisadores e profissionais. Belo Horizonte: Ed. UFMG, 2003. Cap.12, p.153-182.

FREEMAN, L.C. Centrality in social networks: conceptual clarification. Social Networks, Amsterdam, v.1, n.3, p.215-239, 1978/1979.

HANNEMAN, R.A. Introducción a los métodos del análisis de redes sociales. Riverside: Universidad de California, 2001. Disponível em: $<$ http://revista-redes.rediris.es/webredes/> Acesso em: 20 fev. 2006.

HAYTHORNTHWAITE, C. Social network analysis: an approach and technique for the study of information exchange. Library \& Information Science Research, Norwood, v.18, n.3, p.323-342, Autumn 1996.

KOSSINETS, G.; WATTS, D.J. Empirical analysis of an evolving social network. Science, New York, v.311, n.5757, p.88-90, 6 January 2006.

LESCA, H.; ALMEIDA, F.C. Administração estratégica da informação. Revista de Administração, São Paulo, v.29, n.3, p.66-75, jul./set. 1994.

MARTELETO, R.M. Análise de redes sociais - aplicação nos estudos de transferência da informação. Ciência da Informação, Brasília, v.30, n.1, p.71-81, jan./abr. 2001. 
MATHEUS, R.F.; SILVA, A.B.O. e. Análise de redes sociais como método para a Ciência da Informação. DataGramaZero - Revista de Ciência da Informação, Rio de Janeiro, v.7, n.2, abr. 2006. Disponível em: <http://www.dgz.org.br/abr06/Art_03.htm> Acesso em: 27 abr. 2006.

MOLINA, J.L.; AGUILAR, C. Identidad étnica y redes personales entre jóvenes de Sarajevo. Revista Iberoamericana de Filosofía, Política y Humanidades, Barcelona, v.5, n.12, jul./dic. 2004.

MONTALLI, K.M.L.; CAMPELLO, B. dos S. Fontes de informação sobre companhias e produtos industriais: uma revisão de literatura. Ciência da Informação, Brasília, v.26, n.3, set./dez. 1997.

MUELLER, S.P.M. O periódico científico. In.: CAMPELLO, B.S.; CENDÓN, B.V.; KREMER, J.M.(Orgs.) Fontes de informação para pesquisadores e profissionais. Belo Horizonte: Ed. UFMG, 2003. Cap.5, p.73-96.

NONAKA, I.; TAKEUCHI, H. Criação de conhecimento na empresa: como as empresas japonesas geram a dinâmica da inovação. Rio de Janeiro: Campus, 1992.

OTTE, E.; ROUSSEAU, R. Social network analysis: a powerful strategy, also for the information sciences. Journal of Information Science, Cambridge, v.28, n.6, p.441-453, Dec. 2002.

PONJUÁN DANTE, G. Gestión de información: dimensiones e implementación para el éxito organizacional. Rosario: Nuevo Parhadigma, 2004.

TOMAÉL, M.I.; ALCARÁ, A.R.; DI CHIARA , I.G. Das redes sociais à inovação. Ciência da Informação, Brasília, v.34, n.2, maio/ago. 2005.

TOMAÉL, M.I. et al. Redes sociais e inteligência local: espaços da informação. In.: SEMINÁRIO LATINO-IBEROAMERICANO DE GESTIÓN TECNOLÓGICA, 11., 2005, Salvador. Anais... Salvador: ALTEC, 2005, p.1-14. 
UGARTE, D. de. Analizando redes sociales. 2004. Disponível em: <http://www.lasindias.com/curso_redes/curso_redes_1.html> Acesso em: 18 fev. 2005.

WATTS, D.J. The “new” science of networks. Annual Review of Sociology, Palo Alto, v.30, p.243-270, Aug. 2004.

\section{Jorge Luis Rodrigues}

Aluno do Curso de Biblioteconomia da Universidade Estadual de Londrina (UEL), Bolsista Iniciação Científica da Fundação Araucária - jorluisrodrigues@uel.br

\section{Maria Inês Tomaél}

Professora do Departamento de Ciência da Informação da UEL, doutora em Ciência da Informação pela UFMG - mitomael@uel.br

Recebido em: 26/07/2007

Aceito para publicação em: jan/2008 